\title{
Estimating juvenile copepod growth rates: corrections, inter-comparisons and recommendations
}

\author{
W. J. Kimmerer ${ }^{1, *}$, A. G. Hirst ${ }^{2}$, R. R. Hopcroft ${ }^{3}$, A. D. McKinnon ${ }^{4}$ \\ ${ }^{1}$ Romberg Tiburon Center, 3152 Paradise Drive, Tiburon, California 94920, USA \\ ${ }^{2}$ British Antarctic Survey, High Cross, Madingley Road, Cambridge CB3 0ET, UK \\ ${ }^{3}$ Institute of Marine Science, University of Alaska Fairbanks, Fairbanks, Alaska 99775-7220, USA \\ ${ }^{4}$ Australian Institute of Marine Science, PMB 3, Townsville MC, Queensland 4810, Australia
}

\begin{abstract}
The 2 most common experimental methods used to estimate rates of juvenile growth in marine copepods are the molt rate (MR) method, and the artificial cohort (AC) method. Recently, we showed the equations used in the MR method to be incorrect, and proposed a modified molt rate (MMR) method. Here, using statistical and model approaches, we compare the AC and MMR methods under various scenarios to quantify their errors. Although the AC and MMR methods both use a combination of field sampling and simulated in situ incubations to estimate somatic growth, they differ in several important characteristics. The AC method determines growth by the change in mean weight during incubation. Mean weight of copepods in the samples can be determined directly, or inferred from mean weight by life stage or from length-weight regressions. We show that substantial error is avoided only if weights are measured directly $\left(\mathrm{AC}_{\text {direct }}\right)$. The $\mathrm{AC}_{\text {direct }}$ method is insensitive to variable age within stage due to mortality or variable recruitment in the sampled population, an important advantage over the MMR method. However, the $\mathrm{AC}_{\text {direct }}$ method is sensitive to variation in growth rate during incubation, which does not affect the MMR method. We therefore recommend that most experimental estimates of growth rate should apply the $\mathrm{AC}_{\text {direct }}$ method, with the MMR as a suitable alternative provided its biases are considered. An indirect method based on life stage is biased and we no longer recommend it, and an indirect method based on length-weight regression provides an intermediate level of bias.
\end{abstract}

KEY WORDS: Growth rate $\cdot$ Copepoda $\cdot$ Methods $\cdot$ Molt rate

\section{INTRODUCTION}

Copepods dominate the mesozooplankton of the world's oceans, play key roles in grazing and nutrient regeneration, and link microbial processes with the production of higher trophic levels (Verity \& Smetacek 1996). To understand grazing regulation of phytoplankton and microzooplankton production and the supply of food to higher trophic levels requires knowledge of growth and mortality of mesozooplankton. In contrast to the extensive history of estimation of primary production in the oceans, relatively few measurements have been made of mesozooplankton production. Thus, although copepods are generally regarded as dominating epipelagic mesozooplankton production (but see Hopcroft \& Roff 1998a), their secondary production has not been adequately quantified. The recent trend toward representing growth rates of copepods through reproductive rate ignores the real differences between somatic growth and reproduction (Hopcroft \& Roff 1998b, Calbet et al. 2000, Hirst \& Bunker 2003).

We discuss here only demographic methods of estimating growth rate, since alternative methods have not yet achieved widespread success. Three methods have been widely used to determine growth of juvenile copepods: the natural cohort (hereafter NC) method, the artificial cohort (hereafter AC) method, and the molt rate (hereafter MR) method. All make use of the unambiguous progression of life stages in free-living 
copepods, which comprise a series of 13 readily identifiable life-history stages. The weight of each developmental stage exceeds that of the preceding stage, except for those early naupliar stages that do not feed (e.g. Ikeda \& Hirakawa 1996). The NC method is based entirely on field sampling, the AC method uses incubation to determine weight gain over time, and the MR method uses incubation to establish duration of life stages. The latter 2 methods can be applied to populations that lack clearly discernible cohorts. For completeness we begin by describing each of the 3 methods in detail.

Natural cohort method. Some of the earliest estimates of secondary production in natural systems come from the application of natural cohorts to marine benthic communities (e.g. Boysen-Jensen 1919). The $\mathrm{NC}$ method requires no manipulation or artificial incubation of animals, but merely frequent, repeated sampling of a population over some time interval. Growth is calculated by following a distinct population size or stage feature, or cohort over time. The cohort method was first employed on copepods by Russian workers (Winberg 1971) and has been applied to field populations of copepods (e.g. McLaren 1978). In copepods, exponential growth is generally assumed, and temporal changes in weight or size in the cohort are measured.

The principal assumption underlying this method is that the same population is being sampled at each interval. The method also requires a pulse of reproduction that subsequently progresses through the life stages. These requirements are seldom met in real field conditions. Advection and mixing in open waters can cause violations of the key assumption, and sampling variability introduces error into the estimates. Few marine copepods produce cohorts that can be indisputably traced through time. In addition, the need for frequent sampling can limit the practical applications of this technique. We therefore do not consider this method further.

Modified molt rate method. The original molt rate method has been applied in $\sim 30$ studies over $25 \mathrm{yr}$ to determine growth rates of juvenile copepods (see Hirst et al. 2005). Exponential growth is generally assumed, and the change in mean weight of consecutive stages $(i$ and $i+1)$ from the field population are attributed to a period defined by the duration of Stage $i$. Stage durations are generally determined from experimental incubations. Hirst et al. (2005) demonstrated that the equation for growth using this approach is incorrect, and produces results up to 1 order of magnitude in error. In this paper we examine only the modified molt rate (MMR) method, in particular Hirst et al.'s (2005) Eq. (6) for stage duration from molt rates and Eq. (22) for growth. Both of these equations assume that age is uniform within stage. Hirst et al. (2005) provide equations that can be applied when mortality produces a non-uniform distribution of age within stage, but these equations are generally impracticable because mortality is so difficult to measure in the field. Thus, we apply the following equations (rearranged from those in Hirst et al. 2005):

$$
D_{i}=\frac{T}{M_{i}}
$$

where $D_{i}$ is the estimated duration of Stage $i, T$ is the duration of the incubation, and $M_{i}$ is the fraction that molted from Stage $i$ to Stage $i+1$ during the incubation. The growth rate $g_{i 1}$, which applies between Stages $i$ and $i+1$, is calculated from the durations and weights of Stages $i$ and $i+1$ :

$$
\begin{aligned}
F & =\frac{g_{i 1}\left(D_{i}+D_{i+1}\right)}{2}-\ln \left(\frac{W_{i+1}}{W_{i}}\right) \\
& +\frac{\ln \left(\mathrm{e}^{\frac{g_{i 1} D_{i+1}}{2}}-\mathrm{e}^{\frac{-g_{i 1} D_{i+1}}{2}}\right)}{g_{i 1} D_{i+1}}-\frac{\ln \left(\mathrm{e}^{\frac{g_{i 1} D_{i}}{2}}-\mathrm{e}^{\frac{-g_{i 1} D_{i}}{2}}\right)}{g_{i 1} D_{i}}
\end{aligned}
$$

where $W_{i}$ and $W_{i+1}$ are weights in Stages $i$ and $i+1$. This equation can be solved for $g_{i 1}$ at $F=0$ by iteration or using an optimizer. Since Eq. (2) requires estimates of duration of both Stages $i$ and $i+1$, growth rate of copepodite Stage 5 cannot be estimated by the MMR method (Hirst et al. 2005).

Artificial cohort method. The AC method for estimating growth rates of continuously reproducing copepod populations (Kimmerer \& McKinnon 1987) has been widely applied in the field (Table 1), and in laboratory rearing experiments commenced with eggs spawned over a short time interval. Exponential growth is generally assumed, and the weight gain over time in an artificially created cohort is estimated. In applying the artificial cohort method, it is assumed that the growth rate is not altered by collection, handling, or incubation conditions, and that the growth rates are representative of those in the field. Cohorts may broaden during the course of the experiment through variability in individual growth rate (Hopcroft et al. 1998b, McKinnon \& Duggan 2003).

The method described by Kimmerer \& McKinnon (1987) involved the collection of a plankton sample, then the creation of artificial cohorts by passing the sample through 1 filter or through several filters of successively larger mesh size. In this design, the mesh sizes were chosen to select a specific range of stages or sizes of copepods. Given sufficient care, an artificial cohort can be produced rapidly and the filtration does not damage the copepods. However, some copepods from outside the targeted size range of the screens can 'leak' into the artificial cohort. 
Table 1. Applications of the Kimmerer \& McKinnon (1987) artificial cohort method. Temp.: ambient mean temperature or range; MR: experiments that measured molting rates alone and not growth; $\mathrm{C}$ : copepodite stages; N: naupliar stages

\begin{tabular}{|c|c|c|c|c|c|}
\hline $\begin{array}{l}\text { Location } \\
\text { Species }\end{array}$ & Temp. & Weight method & $\begin{array}{l}\text { Growth rate } \\
\left(\mathrm{d}^{-1}\right)\end{array}$ & $\begin{array}{l}\text { Incubation } \\
\text { period }(\mathrm{h})\end{array}$ & Source \\
\hline \multicolumn{6}{|l|}{ Australia } \\
\hline Acartia fancetti & $11-22$ & Mean weight of stage & $0.025-0.26$ & $26-50$ & Kimmerer \& McKinnon (1987) \\
\hline \multicolumn{6}{|l|}{ Skagerrak } \\
\hline Centropages typicus & $16-17$ & Length-weight & $0.24-0.77$ & 24 & Peterson et al. (1991) \\
\hline Temora longicornis & & regression & $0.15-0.56$ & & \\
\hline Paracalanus parvus & & & $0.16-0.48$ & & \\
\hline Pseudocalanus spp. & & & $0.12-0.35$ & & \\
\hline Calanus finmarchicus & & & $0.01-0.14$ & & \\
\hline Acartia longiremis & & & $0.15-0.24$ & & \\
\hline \multicolumn{6}{|l|}{ Norway } \\
\hline Temora longicornis & 18 & $\begin{array}{l}\text { Length-weight } \\
\text { regression }\end{array}$ & $0.00-0.32$ & $\begin{array}{l}1 \text { sample } \\
(24 \mathrm{~h})^{-1}\end{array}$ & Hernández-León et al. (1995) \\
\hline \multicolumn{5}{|l|}{ Canary Islands } & \\
\hline \multicolumn{6}{|l|}{ Jamaica } \\
\hline Oikopleura dioica & & Length-weight & $1.38-3.12$ & 120 & Hopcroft \& Roff (1995) \\
\hline Parvocalanus crassirostris & & regression & $0.24-0.79$ & $\begin{array}{l}1 \text { sample } \\
(24 \mathrm{~h})^{-1}\end{array}$ & \\
\hline \multicolumn{6}{|l|}{ Jamaica } \\
\hline Acartia spp. & 28 & Length-weight & $0.25-1.43$ & 120 & Hopcroft et al. (1998b) \\
\hline Centropages velificatus & & regression & $0.70-1.00$ & 1 sample & Hopcroft \& Roff $(1998 b, c)$ \\
\hline Paracalanus aculeatus & & & $0.25-1.26$ & $(24 h)^{-1}$ & \\
\hline Parvocalanus crassirostris & & & $0.44-1.08$ & & \\
\hline Temora turbinata & & & $0.34-1.23$ & & \\
\hline Corycaeus spp. & & & $0.10-0.36$ & & \\
\hline Oithona nana & & & $0.40-0.91$ & & \\
\hline Oithona simplex & & & $0.17-0.53$ & & \\
\hline \multicolumn{6}{|l|}{ France } \\
\hline Acartia bifilosa & & $\begin{array}{l}\text { Length-weight } \\
\text { regression }\end{array}$ & $0.03-0.14$ & 72 & Irigoien \& Castel (1995) \\
\hline \multicolumn{6}{|l|}{ Agulhas Bank } \\
\hline Calanus agulhensis & $17-18$ & $\begin{array}{l}\text { Length-weight } \\
\text { regression }\end{array}$ & $0.19-0.46$ & 24 & Peterson \& Hutchings (1995) \\
\hline \multicolumn{6}{|l|}{ North Sea } \\
\hline Temora longicornis & $6-16$ & - & MR & 24 & Klein Breteler et al. (1998) \\
\hline Pseudocalanus elongatus & & & MR & & \\
\hline \multicolumn{6}{|l|}{ Plymouth } \\
\hline Calanus helgolandicus & 15 & - & MR & 48 & Shreeve et al. (1998) \\
\hline \multicolumn{6}{|l|}{ Alboran Sea } \\
\hline Centropages typicus & 17 & $\begin{array}{l}\text { Volume-weight } \\
\text { relationship }\end{array}$ & $<0.01-0.27$ & $24-26$ & Calbet el al. (2000) \\
\hline \multicolumn{6}{|l|}{ Georges Bank } \\
\hline Calanus finmarchicus & & $\begin{array}{l}\text { Volume-weight } \\
\text { relationship }\end{array}$ & $\begin{array}{l}\text { C: }-0.09 \text { to } 0.31 \\
\text { N: }-0.07 \text { to } 0.20\end{array}$ & 48 & Campbell et al. (2001a) \\
\hline \multicolumn{6}{|l|}{ Indian Ocean } \\
\hline \multirow[t]{2}{*}{ Mixed calanoid guild } & $21-31$ & Volume-weight & C: 0.38 & 48 & McKinnon \& Duggan (2003) \\
\hline & & relationship & $\mathrm{N}: 0.43$ & 24 & \\
\hline \multirow[t]{2}{*}{ Mixed cyclopoid guild } & & & C: 0.28 & 48 & \\
\hline & & & $\mathrm{N}: 0.38$ & 24 & \\
\hline \multicolumn{6}{|l|}{ Great Barrier Reef } \\
\hline Mixed calanoid guild & $22-30$ & Volume-weight & C: $0.12-0.53$ & 48 (2 expts & McKinnon et al. (2005) \\
\hline Mixed cyclopoid guild & & relationship & C: $0.16-0.48$ & $\begin{array}{l}\text { sampled also } \\
\text { after } 24 \mathrm{~h} \text { ) }\end{array}$ & \\
\hline \multicolumn{6}{|l|}{ Gulf of Alaska } \\
\hline $\begin{array}{l}\text { Neocalanus flemingeri/ } \\
\text { plumchrus }\end{array}$ & $5-9$ & $\begin{array}{l}\text { Length-weight } \\
\text { regression }\end{array}$ & $0.01-0.28$ & 120 & Liu \& Hopcroft (2006a) \\
\hline \multicolumn{6}{|l|}{ Gulf of Alaska } \\
\hline Metridia pacifica & $5-14$ & $\begin{array}{l}\text { length-weight } \\
\text { regression }\end{array}$ & $0.01-0.28$ & 96 or 120 & Liu \& Hopcroft (2006b) \\
\hline \multicolumn{6}{|l|}{ Gulf of Alaska } \\
\hline $\begin{array}{l}\text { Calanus marshallae, } \\
\text { C. pacificus }\end{array}$ & $5-14$ & $\begin{array}{l}\text { Length-weight } \\
\text { regression }\end{array}$ & $0.03-0.30$ & 96 or 120 & $\begin{array}{l}\text { H. Liu \& R. R. Hopcroft } \\
\text { (unpubl.) }\end{array}$ \\
\hline
\end{tabular}


Various modifications of the original approach have been applied. Hopcroft \& Roff $(1998 b, c)$ and Hopcroft et al. $(1998 \mathrm{a}, \mathrm{b})$ collected a whole water sample and applied successively larger mesh sizes to produce a series of artificial cohorts that spanned the entire size range of the target zooplankton community. Liu \& Hopcroft (2006a) performed 1 set of experiments using the conventional protocol, and another with the artificial cohort composed of single stages picked from the sample (Single Stage AC or $\mathrm{AC}_{\mathrm{SS}}$ ).

Important considerations in AC experiments include (1) growth is determined only for the stages of copepods incubated, (2) in mixed plankton, different developmental stages are isolated for different species (Peterson et al. 1991), and (3) there is limited control over numbers and kinds of target species present. Below we raise several issues about the way the method has been applied to copepods, because growth in length and growth in weight are decoupled. These issues do not arise when the method is used for taxa in which growth in weight and length are closely coupled (e.g. appendicularians, Hopcroft et al. 1998a).

If mean weight of copepods before and after incubation is determined by direct measurement $\left(\mathrm{AC}_{\text {direct }}\right)$ the growth rate is:

$$
g_{\mathrm{AC}_{\text {direct }}}=\frac{\ln \left(\frac{W_{T}}{W_{0}}\right)}{T}
$$

where $W_{T}$ is the arithmetic mean weight of copepods at the end of the incubation, $W_{0}$ is that at the beginning, and $T$ is the incubation period in days. However, copepod weight is seldom measured directly in applications of the AC method (McKinnon 1996, Campbell et al. 2001b: both from cohorts commenced from eggs), and in field situations this measurement can be difficult. The small juvenile stages of many copepods are difficult to sort at sea, and fixation results in some weight loss (Kimmerer \& McKinnon 1986).

Consequently, indirect methods of estimating mean weight have usually been applied in the AC method (see Table 1). Kimmerer \& McKinnon (1987), for example, determined the stage frequencies in each sample, and then applied independently-derived measurements of the mean weight of live field-caught copepods $\left(\mathrm{AC}_{\text {stage }}\right)$. Growth rates were then determined from the proportion of total copepods in each stage, and the mean weight of the stage in the field:

$$
g_{\mathrm{AC} \text { stage }}=\frac{\ln \left(\frac{\sum W_{i} P_{T, i}}{\sum W_{i} P_{0, i}}\right)}{T}
$$

where $W_{i}$ is the arithmetic mean weight of Stage $i$ in the field, $P_{0, i}$ is the proportion of copepods in Stage $i$ at the start of the incubation, and $P_{T, i}$ is the propor- tion in Stage $i$ after the incubation Period $T$ (d). The right-hand side of Eq. (4) can be seen as the slope of a regression of log mean weight (calculated from stage) over time; when samples are processed in a time-series incubation the growth rate is calculated from the slope, with Eq. (4) generalized for multiple time steps.

In most applications of the AC method mean weight has been determined using length-weight regressions $\left(\mathrm{AC}_{L W}\right)$ (Table 1), in which case growth is given by:

$$
g_{\mathrm{AC}_{L W}}=\frac{\ln \left(\frac{W_{L T}}{W_{L 0}}\right)}{T}
$$

where $W_{L 0}$ and $W_{L T}$ are the mean weights of the samples at Times 0 and $T$, respectively, based on measured lengths and length-weight regression determined on field-collected copepods.

Although growth in weight is continuous in time, growth in length is discontinuous. Sharp changes in length occur upon molt in copepods, while changes in length within a stage are very slight, perhaps negligible. Changes in length are therefore strongly decoupled from changes in weight, particularly across time intervals less than the duration of the life stages. The resulting stepwise relationship of length to weight is obvious in some length-weight regressions when the stages are labelled (e.g. see Fig. 6 in Kimoto et al. 1986). Thus, estimates of weight based on lengthweight regressions are more similar to those based on mean weights of stages than those based on direct measurement of weight.

The $\mathrm{AC}_{L W}$ method has several variants. The weight of all copepods can be determined from their length using the regression and an arithmetic mean calculated. An alternative is to use a median or trimmed mean, in which some fraction (say $10 \%$ ) of the ordered distribution of weights is omitted before the mean is calculated. This helps to reduce the influence of the few large (or small) copepods that may have 'leaked' into the sample. Another way of minimizing the influence of outliers is to calculate mean length and determine the corresponding weight (Hopcroft et al. 1998a,b).

Objectives. In this paper we compare growth rate methods to determine the likely size of errors, which factors contribute most to inaccuracies, and under what circumstances each method would be most appropriate. The objectives of this study were to (1) clarify assumptions and conditions for use of both the AC and MMR methods, (2) determine which components may contribute most to the error in measurement, (3) compare results between the methods quantitatively, and (4) determine the conditions under which each method is most appropriate. 


\section{METHODS}

We used analytical and simulation modeling and statistical analysis to assess the alternative methods of estimating growth rate. In all analyses, timedependent parameters were scaled to the duration of Copepodite Stage 1 (C1) to eliminate redundant parameters. For example, growth rate in simulations was selected by specifying the ratios of weight on entry to successive stages irrespective of duration.

Statistical consideration of sample size. In general sampling effort is determined from objectives of the measurement, target confidence limits of the result, and underlying variability. In growth measurements, the number of copepods is under control of the experimenter, with a relatively small penalty for using large numbers provided the container size is adequate to prevent crowding effects.

In applying the $\mathrm{AC}$ method using a single, selected Life Stage $i$ and determining actual mean weight, the minimum number of copepods in the initial and final samples is:

$$
N_{\min t}=\frac{2 s^{2}{ }_{\log w}}{\left[\mathrm{CV} \cdot T \cdot \log \left(W_{i+1} / W_{i}\right)\right]^{2}}
$$

where $s^{2} \log _{w}$ is the variance in log weight of the copepods, CV is the target coefficient of variation of a single growth rate measurement, $T$ is the incubation time as a fraction of the duration of the selected life stage, and $W_{i}$ is the mean weight of Stage $i$. We calculated the minimum number of copepods for a variety of values of the input parameters.

The MMR method relies on an estimate of the stage duration based on the fraction of copepods that molt out of the target stage and the fraction that molt out of the subsequent stage. The experimenter has control over the number of copepods used in the incubation, and the fraction molting has a binomial distribution. We estimated error in growth rate using Eqs. (1) \& (2) by sampling from a binomial distribution with various assumed numbers of copepods using the same terms as in Eq. (6) above, and then interpolated Eq. (6) to determine the numbers of copepods needed for selected values of the stage duration. Samples were labeled as indeterminate if either all or none of the copepods remained in the selected life stage.

Individual-based model. We developed a simple individual-based model to exam- ine the effects of population parameters and experimental conditions on results from the AC and MMR methods. Details of the model are provided in Appendix 1, and key points are summarized in Fig. 1 and Tables $2 \& 3$. Parameter values in the model are those in Tables 2 \& 3 except where noted. The relative incubation period $T$ was set to 0.5 in several cases to increase variability and emphasize effects of varying other parameters. Principal assumptions of the model were (1) growth of individuals within a stage is exponential, (2) exuviae are negligible, and (3) no mortality occurs within the simulated incubations.

Briefly, for each experiment the model first establishes a large (100000) population of copepods in Life Stages C1 to C6, with a selected distribution of age, life stage, weight, and length, according to life-history rules. Individual copepods differ in their age (and therefore life stage), and can also vary in relative development rate, and weight and length at age. Recruitment is not modeled explicitly.

Table 2. Parameters of the individual-based model with default values. Asterisks indicate values provided in Table 3. In the model all time parameters and variables are entered as dimensionless numbers with duration of Stage 1 assigned an arbitrary value of 1

\begin{tabular}{|c|c|c|}
\hline Parameter & Function & Initial value \\
\hline \multicolumn{3}{|c|}{ Parameters used to set up population to be sampled } \\
\hline$N$ & Total number of copepods & 100000 \\
\hline$N_{\text {stage }}$ & Number of Life Stages & 6 \\
\hline$D_{i}$ & Duration of Stage $i$ & * \\
\hline$m$ & $\begin{array}{l}\text { Daily mortality (used only to establish age } \\
\text { distribution) }\end{array}$ & 0.2 \\
\hline$G_{i}$ & $\begin{array}{l}\text { Relative growth by stage ( } W \text { on entrance to } \\
\text { next stage/ } W \text { on entrance to current stage) }\end{array}$ & * \\
\hline$W_{0}$ & Initial weight of first life stage & 0.5 \\
\hline$C V_{\text {dtime }}$ & $\begin{array}{l}\text { Coefficient of variation of development times } \\
\text { (a fraction, can be } 0 \text { ) }\end{array}$ & 0.05 \\
\hline$C V_{\mathrm{LW}}$ & Coefficient of variation of log weight & 0.2 \\
\hline$l w \cdot$ params & $\begin{array}{l}\text { Nominal parameters } a \text { and } b \text { for a length- } \\
\text { weight relationship }\end{array}$ & $4.68,3.06$ \\
\hline$G_{\text {pen }}$ & $\begin{array}{l}\text { Fractional reduction in growth rate due to } \\
\text { reduction in food quantity or quality during } \\
\text { incubation }\end{array}$ & 0 \\
\hline \multicolumn{3}{|c|}{ Parameters used in sampling the population } \\
\hline$N_{f}$ & $\begin{array}{l}\text { Target number of copepods per stage for } \\
\text { length-weight relationships and weight } \\
\text { per stage }\end{array}$ & 20 \\
\hline$N_{\text {rep }}$ & Number of replicates for AC measurements & 6 \\
\hline$N_{t}$ & $\begin{array}{l}\text { Target number of copepods per incubation } \\
\text { sample (AC or MMR) }\end{array}$ & 50 \\
\hline$L_{\mathrm{ac}}$ & $\begin{array}{l}\text { Lengths for artificial cohort defining } \\
\text { trapezoidal probability distribution } \\
\text { (emphasizes C1 stage) }\end{array}$ & $\begin{array}{l}0.52,0.66 \\
0.70,0.82\end{array}$ \\
\hline$P_{\min }$ & $\begin{array}{l}\text { Minimum probability of including copepods } \\
\text { of any size in sample }\end{array}$ & 0 \\
\hline$T$ & Incubation time & 1 \\
\hline Trim.pct & $\begin{array}{l}\text { Percent of samples to trim using trimmed L-W } \\
\text { method }\end{array}$ & 10 \\
\hline
\end{tabular}




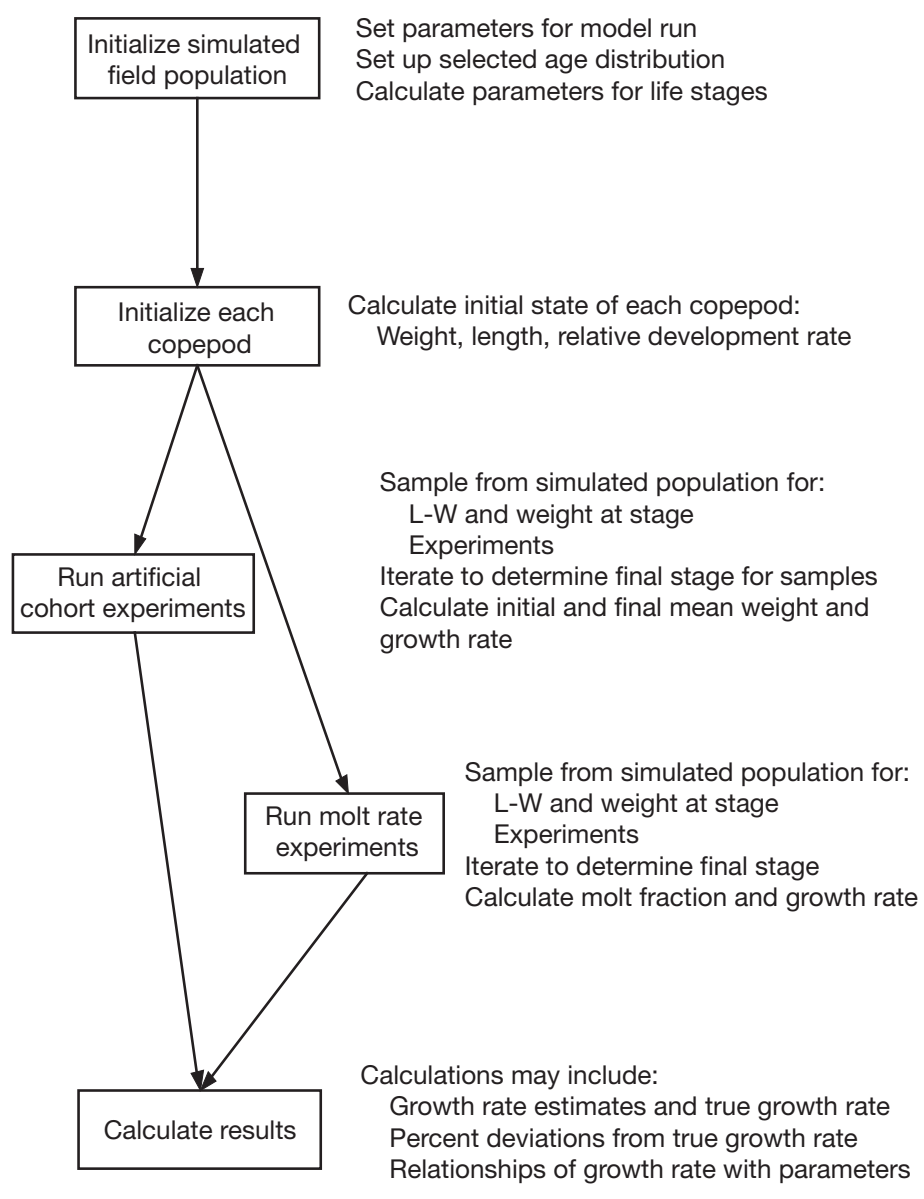

Fig. 1. Flow chart describing design and operation of model. For details, see Appendix 1

The model samples the simulated population to determine length-weight regressions and weight by stage, obtain artificial cohorts, and conduct molt rate experiments. AC experiments may be started with single stages $\left(\mathrm{AC}_{\mathrm{SS}}\right)$, as in the experiments of McKinnon (1996), Campbell et al. (2001b) and Liu \& Hopcroft (2006a), or use a window of copepod lengths to sample

Table 3. Stage duration, and weight and length increments for isochronal and non-isochronal models, latter based loosely on Vidal $(1980 a, b)$

\begin{tabular}{|lcccccccc|}
\hline \multirow{2}{*}{ Parameter } & \multirow{2}{*}{ Symbol } & \multicolumn{7}{c|}{ Stage } \\
\cline { 3 - 9 } & & & C1 & C2 & C3 & C4 & C5 & C6 \\
\hline Isochronal & & & & & & & \\
Stage duration & $D_{i}$ & 1 & 1 & 1 & 1 & 1 & $\infty$ \\
Weight increment & $G_{i}$ & 2 & 2 & 2 & 2 & 2 & - \\
Length increment & $L_{i+1} / L_{i}$ & 1.25 & 1.25 & 1.25 & 1.25 & 1.25 & - \\
Non-isochronal & & & & & & & \\
Stage duration & $D_{i}$ & 1 & 1 & 2 & 4 & 6 & $\infty$ \\
Weight increment & $G_{i}$ & 2 & 2 & 2 & 3.5 & 7 & - \\
Length increment & $L_{i+1} / L_{i}$ & 1.25 & 1.25 & 1.25 & 1.51 & 1.89 & - \\
\hline
\end{tabular}

from the population. Copepods selected for incubation gain weight according to the duration of the incubation and their individual initial conditions and development time. Repeated iterations of the sampling procedure for the same initial population were used to determine variability in results.

Two cases were modeled. In the isochronal case, stage duration and growth were constant across Stages C1 to C5, approximately mimicking the growth pattern of Acartia species (Miller et al. 1977). Many other species have reduced growth and longer stage durations in progressively older copepodite stages. Therefore the non-isochronal case had equal stage durations and growth rates in $\mathrm{C} 1$ and $\mathrm{C} 2$, but progressively increasing durations and decreasing growth rates in subsequent stages.

\section{RESULTS}

\section{Sample size and duration of incubation}

In an $\mathrm{AC}$ experiment the number of copepods needed to achieve a selected target coefficient of variation $(\mathrm{CV})$ decreases as relative incubation time $T$ increases (Fig. 2), but increases with decreasing ratios

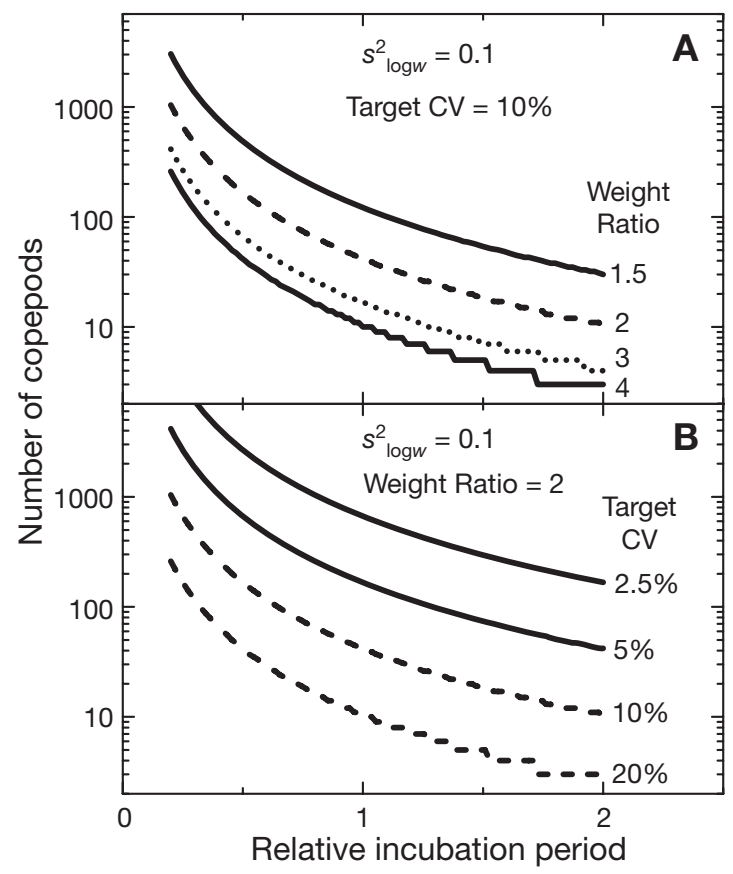

Fig. 2. Number of copepods required to achieve selected coefficients of variation (CV) as function of relative incubation period (incubation period/stage duration) using direct artificial cohort $\left(\mathrm{AC}_{\text {direct }}\right)$ method with individual stages (Eq. 6). (A) Various weight ratios (ratio of weight at end of incubation to that at start) with target CV of $10 \%$; (B) various target CVs for fixed weight ratio of 2 
of weight gain in successive stages (Fig. 2A) and decreasing target CV (Fig. 2B). The number of copepods needed rises sharply as the incubation time decreases below roughly the duration of the selected stage. Thus, for a target $\mathrm{CV}$ of $10 \%$ and a rather typical weight ratio of 2 , only $\sim 40$ copepods are needed in the initial and final samples if incubation time equals the stage duration, but $\sim 130$ are needed if incubation time is about half the stage duration (or alternatively, $\mathrm{CV}$ of the result increases to $20 \%$ if 40 copepods are incubated). Note that only the total number of copepods in the samples, not the number of replicates, influences the calculation of growth rate error.

Similar calculations for the MMR method (Fig. 3A) also show that the number of copepods required decreases with increasing duration of incubation. However, for a target CV of $10 \%$, a weight ratio of 2 , and equal durations of the 2 successive stages, only 13 copepods need be incubated in each stage if the incubation period is $80 \%$ of the actual duration of each
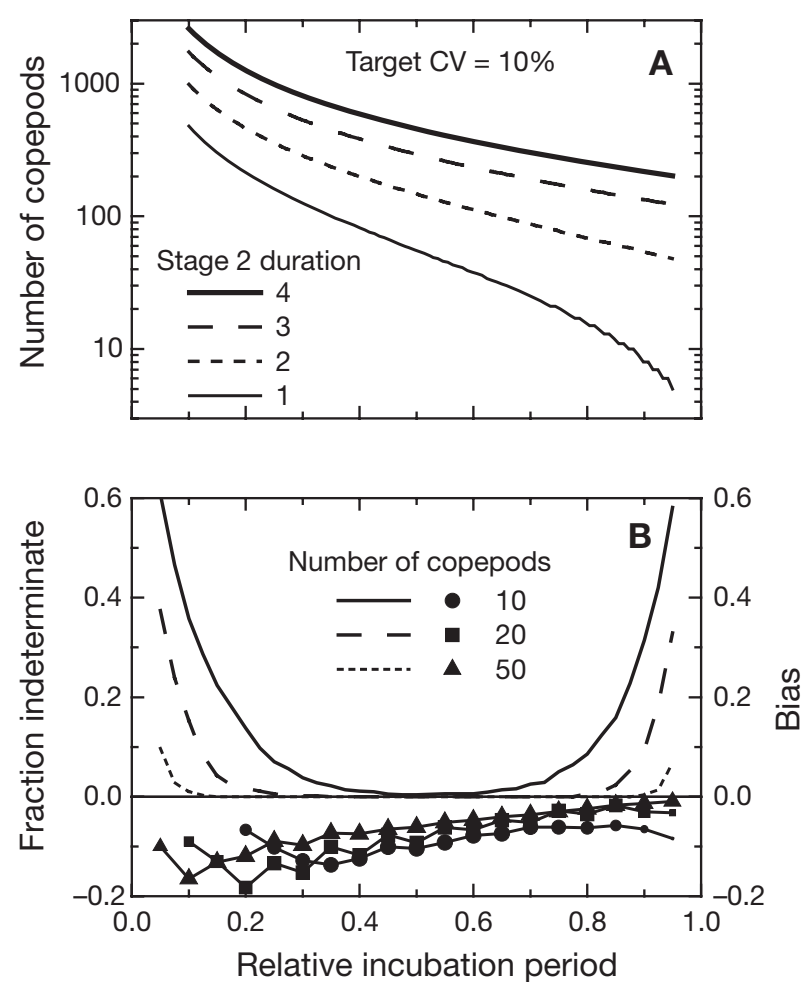

Fig. 3. Error analysis for molt rate method (MMR). (A) Number of copepods required for various durations of Stage $i+1$ relative to Stage $i$, as function of relative incubation period (see legend to Table 2); (B) fraction of incubations that would be indeterminate because either none or all copepods molted (plain curves, left axis), and proportional bias in mean growth rate estimate (curves with symbols, right axis), both as a function of relative incubation period for 3 sample sizes. Sizes of symbols are proportional to fraction of samples in which molt rate could be calculated. Target $\mathrm{CV}=10 \%$, weight ratio $=2$, mortality $=0.2$ stage, while $\sim 50$ are needed at $50 \%$ of the stage duration. If the durations of the 2 stages differ, the number of copepods required increases sharply unless the incubation time differs for each stage (Fig. 3A). However, as the incubation period $T$ approaches either 0 or 1 (relative to the duration of the life stage), the probability of an indeterminate result increases for small numbers of copepods incubated (Fig. 3B). In addition, the magnitude of the bias due to ignoring mortality (Hirst et al. 2005) gets smaller as the incubation period and the number of copepods increase. Thus, the experimental duration is a compromise: it must be long enough to ensure that most of the copepods molt and to minimize bias, but short enough to ensure that they do not all molt. In addition, the more copepods in the incubation, the greater the probability of a successful determination of growth rate.

\section{Individual-based model}

A sample from the populations produced by the model shows the length, weight, and increasing stage distributions that can result (Fig. 4). The effect of decreasing abundance with stage (due to a constant mortality rate, in this case $0.2 \mathrm{~d}^{-1}$ ) can be seen in the graphs for length (Fig. 4A,B). These graphs also show the stairstep variability in length arising because changes in length occur only at the molt, with some variability among individuals allowing for a limited degree of overlap between stages. In contrast, weight increases more or less smoothly with increasing age. In the isochronal case, length and weight increase log-linearly with increasing age and stage (Fig. 4A,C), while the non-isochronal case shows a decline in the rate of gain of log length and weight with increasing age and stage (Fig. 4B,D).

Variability in model output arises from random sampling and from individual variability in growth characteristics among the copepods. The coefficients of variation of relative development time and log weight were selected to be 5 and $20 \%$, respectively (Table 2). Although these values seem reasonable they have not been determined experimentally and would be difficult to measure. Differences between growth estimates with and without variability among individuals are small, showing that most of the variability in model output arises from sampling variability (Fig. 5). The variability increases with increasing life stage in the non-isochronal case, because of declining growth rate and increasing absolute variability of weight within stage in the later stages.

A practical consideration when using the AC method is that imperfect initial screening of samples will introduce some copepods larger or smaller than the size 

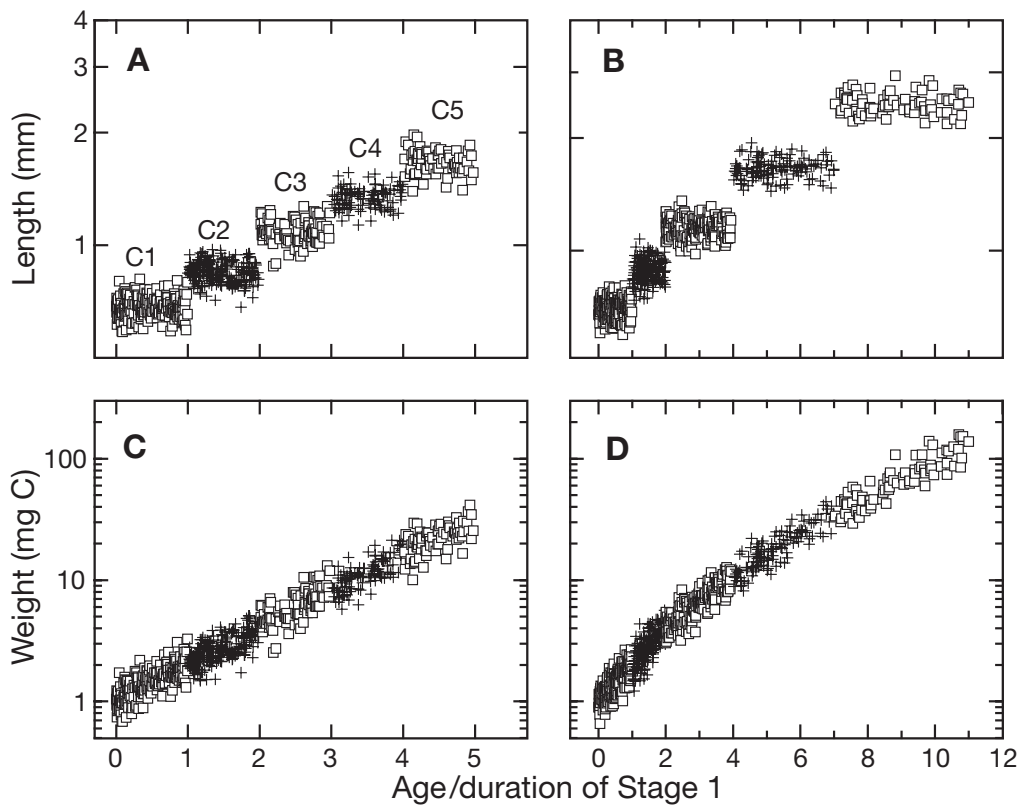

Fig. 4. Attributes of model population for random samples of 1000 copepods across Stages $\mathrm{C} 1$ to $\mathrm{C} 5$. $(\mathrm{A}, \mathrm{B})$ Prosome length versus age (as ratio to duration of first life stage); $(\mathrm{C}, \mathrm{D})$ weight vs. age. $(\mathrm{A}, \mathrm{C})$ isochronal, $(\mathrm{B}, \mathrm{D})$ nonisochronal development. Parameters from Tables 2 to 4

window into the samples to be incubated. These 'leaked' copepods can have a disproportionate impact on the mean weight, particularly if there are a few large copepods. For example, a perfect AC size selection would result in a size distribution entirely within the AC size window (Fig. 6A). The shape of the size distribution in the sample differs from that of the trape-

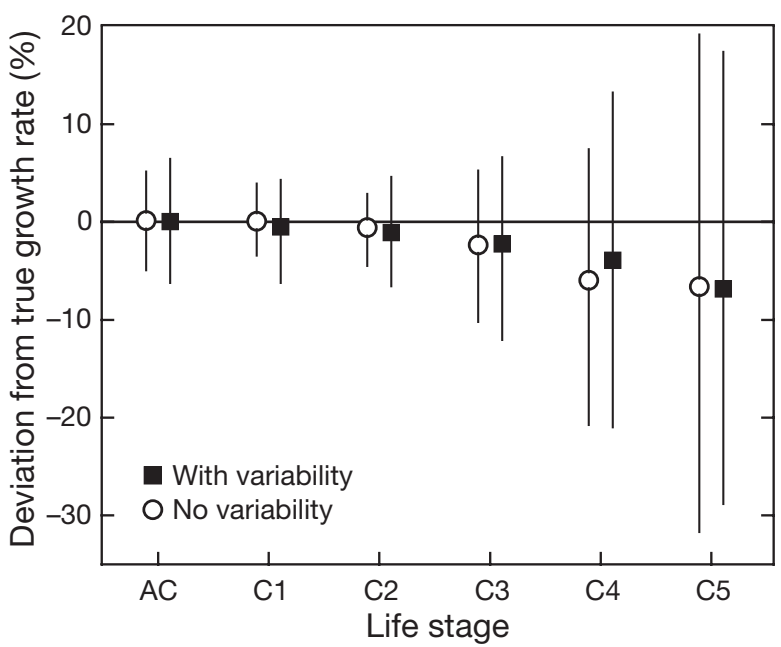

Fig. 5. Effect of individual variability on growth rate estimates. Difference between estimated and true growth rate $\left(\mathrm{d}^{-1}\right)$ for non-isochronal population with and without variability for stage duration $\left(\mathrm{CV}_{\text {dtime }}=0.05\right)$ and log individualweight $\left(\mathrm{CV}_{L W}=0.2\right)$; other parameters as in Table 2. AC: artificial cohort method; C1 to C5: individual stages. Data points means, vertical bars 5 th and 95th percentiles. Mortality $=0$ zoidal window because the size distribution of the population is uneven (Fig. 4). A sample with a small amount of leakage can allow a few copepods from outside the distribution to be sampled (Fig. 6B). Since some of these can be very large, they have an inordinately strong effect on the resulting mean weight, and the variability in growth rate increases with increasing percent leakage (Fig. 6C). Using mean weights from a trimmed L-W relationship reduces the size of the error bars by eliminating the largest and smallest copepods. The amount of improvement decreases as leakage goes up, because the proportion of values trimmed is constant.

When growth is isochronal, the different methods of estimating weight appear less important, but when growth is nonisochronal serious errors can arise when rates are determined using either mean weight of stage or length-weight regressions (Fig. 7). These errors are most severe in the later stages in which growth rate is changing rapidly, and depend somewhat on incubation period. Growth rate estimated using measured mean weight was unbiased and accurate for all stages (Fig. 7A). Growth rate estimated using mean weight by stage from simulated field populations was biased substantially high in the non-isochronal case for the middle Stages, C2 to C4, especially when incubations were short, and less biased as the incubation period approached the duration of the selected stage (Fig. 7B). Growth rate estimated using length-weight regressions was generally less biased, and had less variability, than that using weight by stage (Fig. 7C). The error and bias in true AC experiments (i.e. using a size window) reflected those in the dominant life stages; for example the 2 size windows in Fig. 7 (ACL and $\mathrm{ACH}$ ) captured mainly $\mathrm{C} 1$ and $\mathrm{C} 2$, respectively, and their results are similar to results for these stages.

Variation in age structure of the population has relatively little effect on the $\mathrm{AC}_{\text {direct }}$ method, but can introduce bias and variability in the MMR method (Fig. 8). Increasing variability in the growth estimates from the $\mathrm{AC}_{\text {direct }}$ method with increasing life stage arises because of the increasing duration of the later stages, but is unaffected by age structure. Furthermore, since weight is determined directly in the $\mathrm{AC}_{\text {direct }}$ method, no bias arises from the skewed weight distribution in the model copepod population, although this bias would affect the other AC methods. Although the MMR method gives correct results on average when all ages are equally abundant within a stage, the results deviate from the true value for either increasing 

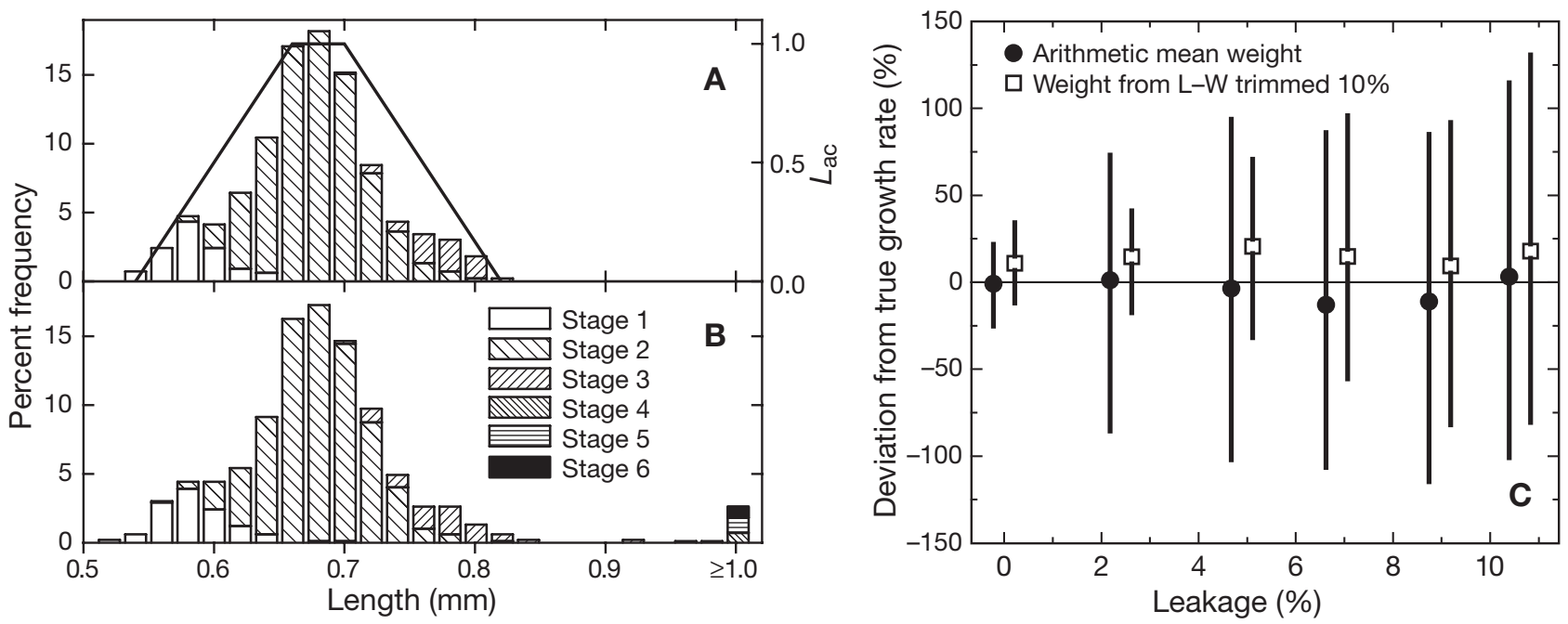

Fig. 6. Effect of inefficient size fractionation on growth rate estimates using AC method for non-isochronal case. Parameters as in Table 2 except as noted below, incubation period $=0.5$. (A) Length distribution from sample of 1000 copepods with AC sampling window $L_{\mathrm{ac}}$ defined by trapezoidal line (right axis), and shading of bars indicating life stage; (B) length distribution with $~ 5.5 \%$ of copepods originating outside selected window; (C) percentage deviation from true growth using arithmetic mean weights $\left(\mathrm{AC}_{\text {direct }}\right)$ and weight from trimmed length-weight $(10 \%$ trim) at various percentages of 'leakage', defined as percentage of copepods outside AC sampling window, $L_{\mathrm{ac}}$. Data points represent means, vertical bars 5th and 95th percentiles

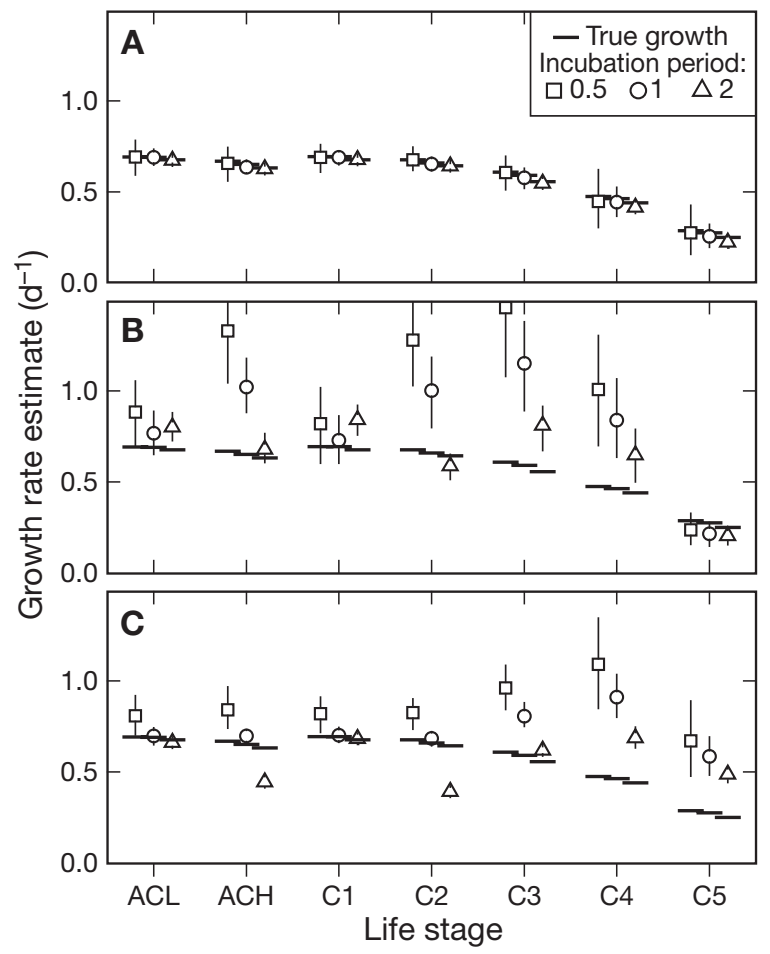

Fig. 7. Effect of growth rate method and relative duration of incubation on growth rate estimates. Comparison of growth rate estimates against true growth rate for non-isochronal case using different methods to determine copepod weights on artificial cohort with default size window (Table 2) (ACL), artificial cohort with size window increased by $0.26 \mathrm{~mm}$, emphasizing $\mathrm{C} 2(\mathrm{ACH})$, and single stages ( $\mathrm{C} 1$ to $\mathrm{C} 5)$. (A) $\mathrm{AC}_{\text {directi }}$ (B) $\mathrm{AC}_{\text {stagei }}(\mathrm{C}) \mathrm{AC}_{L W}$. Results for incubation periods of 0.5 , 1 and 2 times duration of $\mathrm{C} 1$ stage. Data points represent means, vertical bars 5 th and 95th percentiles

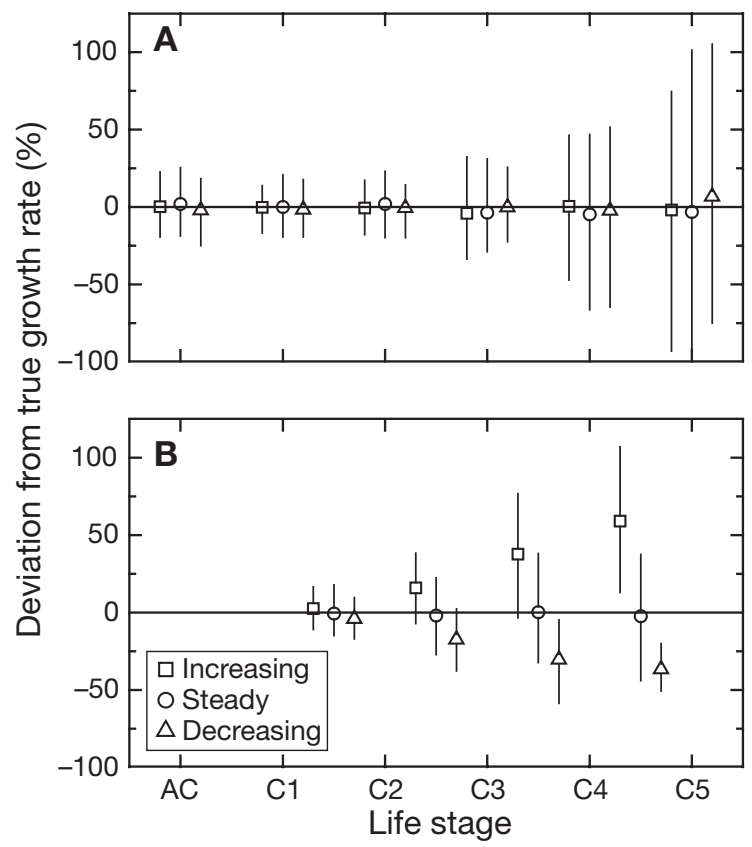

Fig. 8. Comparison of (A) artificial cohort (AC) and (B) molt rate (MMR) methods with varying population age structures. Percentage deviation from true growth rates for nonisochronal case for slopes of log (abundance) vs. age $\left(\mathrm{d}^{-1}\right)$ of $-0.2 \mathrm{~d}^{-1}$ (decreasing), $0.0 \mathrm{~d}^{-1}$ (steady) and $0.2 \mathrm{~d}^{-1}$ (increasing). Other parameters as in Table 2, except relative incubation time was 0.5 and 100 total copepods were used per incubation without replication. (A) AC and Single Stage AC (C1 to C5) methods; (B) MMR method, with data points positioned between the 2 stages over which growth rate is being determined. Results based on 100 measurements with 100 copepods and no replication. Data points represent means, vertical bars 5th and 95th percentiles 


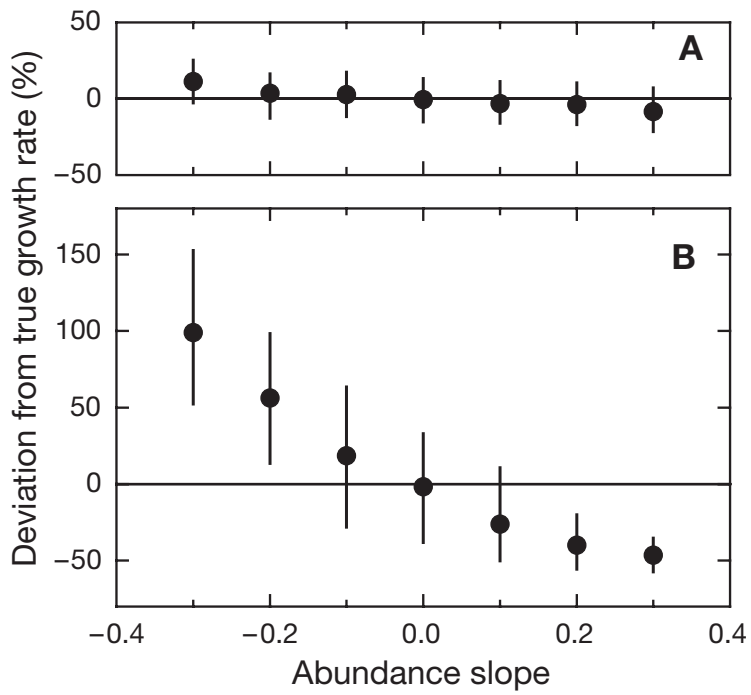

Fig. 9. Effect of population age structure on growth estimates using MMR method showing percentage deviation from true growth using MMR method for various slopes of log (abundance) vs. age (units of slope are $\mathrm{d}^{-1}$ ). (A) Across isochronal stages (C1 and C2); (B) across non-isochronal stages (C4 and C5). Relative incubation period set at 0.5. Data points represent means, vertical bars 5th and 95th percentiles

or decreasing abundance with age. The deviation and variability increase with increasing stage because the oldest stages have longer durations.

The population age distribution strongly influences results from the MMR method in the non-isochronal case (Fig. 9). As the slope of abundance with age varies from negative (mortality or cohort) through zero to positive (possible only in a transient situation), the MMR method provides nearly unbiased estimates in the isochronal case but not in the non-isochronal case (Fig. 9A,B, respectively).

The principal source of bias in the $\mathrm{AC}_{\text {direct }}$ method may be that growth rate, but not development rate, may change under incubation conditions. Changing individual growth rate at the beginning of the incubation results in an equal change in estimated growth rate (data not shown); if the change occurs during the course of the incubation the bias is smaller.

\section{DISCUSSION}

\section{Sample size}

Using the AC method, under most conditions of the target population and an incubation period roughly equal to the duration of 1 stage, only about 40 copepods are needed in the initial and final samples to achieve a reasonable target $\mathrm{CV}$ of $\sim 10 \%$. This calculation does not address replication of subsamples from a single field sample, and the decision to replicate (in any sampling program) depends on the objectives. The original design required replication to validate the method, in particular the constancy of specific growth rate during incubation (Kimmerer \& McKinnon 1987). However, replication is not required (e.g. Hopcroft et al. 1998b, Liu \& Hopcroft 2006a,b) and the reliability of the individual estimate of growth depends not on replication, but on the total number of copepods incubated. The principal advantages of replication are methodological: to verify that growth rates do not diverge excessively among replicates, or are constant during incubation, and that excessive error has not been introduced into a given sample, e.g. through high mortality or leakage of a few large copepods. The advantage of not replicating (in measuring growth rate as with any sampling effort) is that more experimental effort can be directed at principal sources of variation, e.g. temporal and spatial variation. As always, the decision to replicate depends on the objectives of the measurements.

The number of copepods required for a given target $\mathrm{CV}$ decreases with increasing incubation time, although the slope of this relationship diminishes when incubation time is longer than the stage duration (Fig. 2). A long incubation may be undesirable because of the accumulation of bottle effects, especially a decrease in food supply through consumption and settling, and resulting decline in growth rate of the copepods. The optimum incubation may therefore be the duration of the target life stage for the incubation, since this duration results in a low $\mathrm{CV}$ for the number of copepods used. This recommendation implies that incubations should vary with environmental temperature; for example, stage durations may be as short as $4 \mathrm{~h}$ in the tropics (McKinnon et al. 2003) or 4 to $5 \mathrm{~d}$ in sub-arctic waters (Liu \& Hopcroft 2006a,b). Often incubation periods in $\mathrm{AC}$ experiments reported in the literature, however, appear to have been chosen somewhat arbitrarily (Table 1), with 1 to $2 \mathrm{~d}$ common, irrespective of environmental temperature and anticipated stage durations.

Among the methods discussed here, only the $\mathrm{AC}_{\text {direct }}$ method is sensitive to variation in growth rate during the experiment. In addition, the direct measurement of mean weight is more accurate and precise when large numbers of copepods are weighed, a factor with potentially more effect on the required number of copepods than the sampling error discussed above. However, when weighing small numbers of copepods it does not seem possible to distinguish errors from actual variation in their weight, so this error must be minimized based on the investigator's experience and the sensitivity of the measuring equipment. In addition, direct weighing destroys the sample, precluding subsequent 
re-evaluation of stage or species identification, in which case the $\mathrm{AC}_{L W}$ method has some merit.

With the MMR method, relatively few copepods are needed if the incubation period comprises a large fraction of the duration of the target life stages (Fig. 3A). A long incubation also minimizes bias, but it carries 2 risks. The first is that if the measurement is necessary at all, the stage duration will be difficult to predict. The second is that as the incubation time approaches the stage duration, the probability that all the copepods will have molted at the end of the incubation increases (Fig. 3B). If all the copepods molt, the measurement is indeterminate. Therefore, the selection of an incubation period is a compromise between the need for robust experimental statistics, and the need to avoid complete failure of the measurement. This compromise must be based on the experimenter's conservative estimate of the minimum stage duration. Some guidance on the likely stage duration can be obtained from specific literature on closely related species or the general relationship between stage duration and temperature (Hirst et al. 2005).

\section{Growth methods}

None of the methods is perfectly suited to all conditions. The AC methods can suffer from bias when proxies for weights are used (see below), and increased error when the size fractionation is not efficient. The latter is not greatly improved by trimming the data before mean weights are calculated. The $\mathrm{AC}_{\text {direct }}$ method, which we recommend below for most situations, can be biased by growth changes during incubation. The MMR method is strongly biased by nonuniform population age structure.

All these methods assume exponential growth during incubation or sampling intervals. This assumption could be violated by diel variability, which can be accounted for by time-series incubations with short intervals. At some small time scale the growth rate of any individual is unlikely to be exponential. However, we lack the information to address this problem. Furthermore, since these methods are designed to estimate growth in the population as a whole, it is appropriate to average across individuals, which (except in the diel case) should minimize the effect of that variability.

We have demonstrated that substantial bias can arise in the calculation of growth using the AC method when proxies of true experimental weight-either mean stage weights $\left(\mathrm{AC}_{\text {stage }}\right)$ or length-weight regressions $\left(\mathrm{AC}_{L W}\right)$-are used in the non-isochronal case, particularly over periods comparable to stage durations. This bias is clearly discernible when comparing early (isochronal) with late (non-isochronal) life stages (Fig. 7). The largest bias co-occurs with the greatest deviation from constant growth rate, i.e. Stages C2 to $\mathrm{C} 4$. The bias for C5 is smaller because the adult (C6) stage does not grow in our model and therefore the source of this bias vanishes.

How does this bias arise when growth is calculated from mean weight of stage? Assume that an artificial cohort of Stage $i$ is captured at time zero, and its weight is determined simply as the mean weight of the stage. These copepods are then incubated for a period $T$. The expected proportion that molt out of Stage $i$ is $T / D_{i}$ (when age within stage is uniform). The proportion that molt are assigned the mean weight of Stage $i$ +1 , but the mean weight of Stage $i+1$ is a function of both the growth rate and the duration of Stage $i+1$. This is not considered in the formulation of Eqs. (4) \& (5), so both can produce incorrect estimates of growth. In other words, the mean weight of copepods in Stage $i$ +1 is not the same as the mean weight of the copepods that have molted during the incubation, particularly if Stage $i+1$ is longer than Stage $i$.

It is possible to improve Eq. (4), but doing so reveals a significant error. The numerator of this equation is supposed to represent the mean weight of copepods, but in effect it assumes a linear trajectory for mass accumulation rather than an exponential one. This can be improved somewhat by making the numerator a geometric combination of the weights of included stages. Using a geometric combination for the simpler case in which a single stage is selected, and rearranging, gives:

$g_{\mathrm{AC}_{\mathrm{geo}}}=\frac{\ln \left(\frac{W_{i}^{\left(1-M_{i}\right)} W_{i+1}^{M_{i}}}{W_{i}}\right)}{T}=\ln \left(\frac{W_{i+1}}{W_{i}}\right) \frac{M_{i}}{T}=g_{\mathrm{MR}_{i}}$

where $M_{i}$ is the proportion that molts out of Stage $i$ (equivalent to $P_{T, i+1}$ in Eq. 4). The rearranged version of this equation is identical to the unmodified MR method (i.e. $g_{\mathrm{MR}_{\mathrm{i}}}$ ). Therefore, the conceptual and mathematical error in the MR method (Hirst et al. 2005) applies to the $\mathrm{AC}_{\text {stage }}$ method using geometric means; the $\mathrm{AC}_{\text {stage }}$ method using arithmetic means has an additional source of bias (discussed above; see also Fig. 7B).

The AC method using length-weight relationships to determine mean weight $\left(\mathrm{AC}_{L W}\right)$ seems to fall between the direct method and the stage-selected method in terms of the above errors. To the extent that length increases stepwise with increasing stage, the length-weight and stage-based approaches are identical. However, length covaries somewhat with weight within a stage, because some copepods are both heavier and longer than others both before and after incubation. This makes length a somewhat better predictor of mean weight than life stage, but bias can still be substantial (Fig. 7C). 
Calbet et al. (2000), McKinnon \& Duggan (2003) and McKinnon et al. (2005) used an image analysis system to measure both length and width of copepods, which were converted to volume, which was then used to make weight estimates. Presumably this method suffers from some of the same drawbacks as the lengthweight regression method, but may produce more accurate weights by accounting for changes in width (Pearre 1980) and to some extent the condition factor (Durbin \& Durbin 1978) of the copepod during a stage.

A potential drawback of the $\mathrm{AC}_{\text {direct }}$ method is that growth may be altered (a 'growth penalty') as a result of the incubation process. Results of such a penalty are easy to calculate, although there is little quantitative basis from the literature for an estimate of this effect. Development time appears typically less sensitive to incubation conditions than growth rate (Vidal 1980a,b, but see below). Tarling et al. (2006) were unable to discern differences in molt rate over the course of $5 \mathrm{~d}$ when incubating the euphausiid Euphausia superba under starvation conditions, whilst in the same experiments length increment at molt (a growth proxy) was measurably reduced almost immediately (Atkinson et al. 2006). If growth rate changes slowly after the incubation starts (e.g. through a cumulative reduction in feeding rate), time-series experiments should reveal the bias. However, if growth rate changes immediately time series may not help; in that case, comparing mean weight at stage in the incubations and in the field population might reveal the bias if the incubation period is close to the stage duration.

If age within stage is non-uniform then $1 /$ (molt rate) will incorrectly describe stage duration. A non-uniform age structure can result from mortality (Hirst et al. 2005), reproduction varying in time (Miller \& Tande 1993), or differential advection. Hirst et al. (2005) demonstrated that in situ mortality rates can be sufficient to cause substantial errors in predicted stage duration, particularly when stage duration is much greater than average (see their Fig. 7).

Although versions of the MMR equations are available for the case where mortality is present (Hirst et al. 2005), these would be difficult to apply in a real field situation because of the difficulty of estimating mortality. Thus, the ease of application of the MMR method is offset by the biases arising from non-uniform age distribution (Figs. $8 \& 9$ ). The $\mathrm{AC}_{\text {direct }}$ method is free of the issues relating to non-uniform age within stage, but the other AC methods are affected by non-uniform age within stage because of the non-uniform distribution of weights within stage.

An additional complication arises if molting is accelerated by the collection process, in a 'molting burst' (Miller et al. 1984). Molting bursts may be uncommon, however, since they have not been observed by other authors (Grigg \& Bardwell 1982, Runge et al. 1985, Diel \& Klein Breteler 1986). In many studies the molting rate of field-collected copepods is highly variable, possibly as a consequence of food limitation (e.g. Peterson et al. 1991, Peterson \& Hutchings 1995, Richardson \& Verheye 1999). However, variability might also arise from non-uniform age within stage. Additionally, as we have demonstrated when fewer copepods are incubated, or incubations are short relative to the stage duration, the variability in molt rates and hence predicted stage duration increases sharply (Figs. 2 \& 3).

With the MMR method, the durations of the 2 consecutive stages are obtained from incubation, and the weights of each stage are from field samples (Table 4). Neither variable is under control of the investigator, and both are subject to measurement error. In contrast, in the application of the $\mathrm{AC}_{\text {direct }}$ method, weight changes are subject to experimental error, whereas the experimental duration is controlled by the investigator.

Our demonstration of the errors in the estimation of growth rate made with the $\mathrm{AC}$ method is also relevant to some applications of the NC method. In a natural cohort, growth rate is generally inferred from the rate of development in stage or length, and weight is determined from field samples. If weight is determined in each sample, the result is equivalent to the $\mathrm{AC}_{\text {direct }}$ method. However, if weight is determined by stage or from a length-weight relationship, the result is equivalent to the $\mathrm{AC}_{\text {stage }}$ or $\mathrm{AC}_{L W}$ approaches and has similar biases.

Unfortunately, we are forced to conclude that, as with the molt rate method (Hirst et al. 2005), the AC method has been applied in situations where the results are probably biased. The bias may be quite small in the case of copepods with nearly isochronal development, and where incubation period approaches stage duration. However, we have shown that for copepods with decelerating growth rate with increasing age or stage, and for short incubations, the errors can be substantial.

\section{Recommendations}

Although we have outlined the ideal experimental approach, we recognize that tradeoffs are often required between the optimal measurements and the logistics of obtaining them. For example, it may be difficult to obtain weights of copepods from incubated samples, particularly on shipboard, without having to preserve the copepods; uncertainty about growth penalties (i.e. declines in growth during incubation) may make interpretation difficult; and the experimenter may not wish to destroy a sample to determine mean weight. Thus, we provide the following recom- 
Table 4. Comparison of methods for measurement of copepod juvenile growth rate (equations for each given in text). Growth is assumed to be exponential in period considered by each equation. $W_{0}, W_{t}$ : weight at start and end of period over which growth determined, respectively. $A W_{i}, A W_{i+1}$ : arithmetic mean weight of Stages $i$ and $i+1$, respectively; $D_{i}, D_{i+1}$ stage durations; $T_{s}$ T: sampling interval for natural and artificial cohorts, respectively; MMR method from Hirst et al. (2005)

\begin{tabular}{|c|c|c|c|}
\hline Parameter & Natural cohort & $\begin{array}{l}\text { Artificial cohort } \\
\text { (direct weights) }\left[\mathrm{AC}_{\text {direct }}\right]\end{array}$ & Modified molt rate [MMR] \\
\hline \multicolumn{4}{|c|}{ Measurements } \\
\hline Weight & $\begin{array}{l}W_{0}, W_{t} \\
\text { From the field } \\
\text { Subject to measurement } \\
\text { error }\end{array}$ & $\begin{array}{l}W_{0}, W_{t} \\
\text { Weights determined directly } \\
\text { Final weight may be depressed by } \\
\text { incubation conditions } \\
\text { Subject to measurement error }\end{array}$ & $\begin{array}{l}A W_{i}, A W_{i+1} \\
\text { From the field } \\
\text { Subject to measurement error }\end{array}$ \\
\hline Time & $\begin{array}{l}\text { Sampling interval, } T_{S} \\
\text { (under control of } \\
\text { investigator) }\end{array}$ & $\begin{array}{l}\text { Incubation interval, } T \text {, should be } \\
\text { approximate duration of life stages } \\
\text { (under control of investigator) }\end{array}$ & $\begin{array}{l}D_{i}, D_{i+1} \\
\text { Subject to measurement error } \\
\text { Obtained by 1/MR from containment }\end{array}$ \\
\hline \multicolumn{4}{|c|}{ Assumptions } \\
\hline Weight & $\begin{array}{l}\text { Successive samples drawn } \\
\text { from same population } \\
\text { Mortality not size- } \\
\text { dependent }\end{array}$ & $\begin{array}{l}\text { No changes in growth rate as } \\
\text { result of collection or incubation }\end{array}$ & $\begin{array}{l}\text { Uniform age within stage distribution, i.e. } \\
\text { steady-state and zero mortality (can } \\
\text { correct for mortality according to } \\
\text { Hirst et al. 2005) }\end{array}$ \\
\hline Time & $\begin{array}{l}\text { Duration appropriate for } \\
\text { species and conditions }\end{array}$ & $\begin{array}{l}\text { Duration approximately that of } \\
\text { life stages }\end{array}$ & $\begin{array}{l}\text { Incubation duration adequate for } \\
\text { anticipated development times } \\
\text { No change in molt rate as result of } \\
\text { collection or incubation }\end{array}$ \\
\hline \multicolumn{4}{|l|}{ Conditions } \\
\hline & $\begin{array}{l}\text { Presence of discernible } \\
\text { cohort, which can be } \\
\text { followed through time }\end{array}$ & $\begin{array}{l}\text { Suitable for cohort or steady- } \\
\text { state } \\
\text { Low mortality during incubation }\end{array}$ & $\begin{array}{l}\text { Presence of cohorts or mortality can } \\
\text { create problem for measurements of } \\
\text { both } A W \text { and } D \text { (e.g. present Fig. } 8 \text { and } \\
\text { Hirst et al. 2005) }\end{array}$ \\
\hline
\end{tabular}

mendations for making growth rate estimates as an ideal, and it is up to the experimenter to choose the most suitable approach in a given practical situation:

- The $\mathrm{AC}_{\text {direct }}$ method should be applied in most situations, provided growth rate remains constant during incubation. The MMR method is a suitable alternative to $\mathrm{AC}_{\text {direct }}$ if mortality is low and growth of the penultimate stage is not needed; alternative approaches and equations for this stage are given in Hirst et al. (2005)

- In all experiments, some supplemental (time-series) measurements should be made to ensure that growth rate is constant within an incubation, as inferred from the linearity of the increase in log mean weight over time

- If preliminary experiments establish that growth rate is constant during incubation, the duration of incubation should be approximately equal to the anticipated stage duration (when using the AC method), or about $80 \%$ of the stage duration (when using the MMR method) of the target stages

- In cases where growth rate declines during the experiment (i.e. due to reduction in food concentration), incubation time should be reduced and volume increased if necessary to minimize the effects of food limitation, and the number of copepods should be increased to keep the experimental variability to acceptably low levels

- The MMR method or the $\mathrm{AC}_{\text {direct }}$ method with picked copepods should be used if stage-specific growth rates are required

- Because of the mathematical biases demonstrated in this paper, we no longer recommend use of the $\mathrm{AC}_{\text {stage }}$ method, particularly for copepods with nonisochronal development. The biases in the $\mathrm{AC}_{L W}$ method are smaller, but the $\mathrm{AC}_{\text {direct }}$ method is still preferable when its assumptions can be met

- The number of copepods incubated per target species should be at least 40, and ideally more for either method, particularly if weight gain per stage is limited, or incubation is short relative to the stage duration. Whether to replicate depends on the objective, although it can be useful to bolster claims about the reliability of results.

Acknowledgements. W.J.K. was supported by National Science Foundation Grant OCE-0351850. A.G.H. was supported by the Discovery 2010 Flexicon project at British Antarctic Survey. R.R.H. was supported under NSF Grant OCE-0105236. A.D.M. was supported by the 'Scientific Visits to Europe' program of the Australian Academy of Science. 


\section{LITERATURE CITED}

Atkinson A, Shreeve RS, Hirst AG, Rothery P and 5 others (2006) Natural growth rates of Antarctic krill, Euphausia superba. II. Predictive models based on food, temperature, body length, sex and maturity stage. Limnol Oceanogr 51:973-987

Boysen-Jensen P (1919) Valuation of the Limfjord. I. Studies on the fish food in the Limfjord. 1909-1917 Rep Dan Biol Stn 26:1-44

Calbet A, Trepat I, Arin L (2000) Naupliar growth versus egg production in the calanoid copepod Centropages typicus. J Plankton Res 22:1393-1402

Campbell RG, Runge JA, Durbin EG (2001a) Evidence for food limitation of Calanus finmarchicus production rates on the southern flank of Georges Bank during April 1997. Deep-Sea Res 48:531-549

Campbell RG, Wagner MM, Teegarden GJ, Boudreau CA, Durbin EG (2001b) Growth and development rates of the copepod Calanus finmarchicus reared in the laboratory. Mar Ecol Prog Ser 221:161-163

Diel S, Klein Breteler WCM (1986) Growth and development of Calanus spp. (Copepoda) during spring phytoplankton succession in the North Sea. Mar Biol 91:85-92

Durbin EG, Durbin AG (1978) Length and weight relationships of Acartia clausi from Narragansett Bay, RI. Limnol Oceanogr 23:958-969

Grigg H, Bardwell SJ (1982) Seasonal observations on moulting and maturation in stage $\mathrm{V}$ copepodites of Calanus finmarchicus from the Firth of Clyde. J Mar Biol Assoc UK 62:315-327

Hernández-León S, Almeida C, Montero I (1995) The use of aspartate transcarbamylase activity to estimate growth rates in zooplankton. ICES J Mar Sci 52:377-383

Hirst AG, Bunker AJ (2003) Growth of marine planktonic copepods: global rates and patterns in relation to chlorophyll $a$, temperature and body weight. Limnol Oceanogr 48:1988-2010

Hirst AG, Peterson WT, Rothery P (2005) Errors in juvenile copepod growth rate estimates are widespread: problems with the moult rate method. Mar Ecol Prog Ser 296: 263-279

Hopcroft RR, Roff JC (1995) Zooplankton growth rates: extraordinary production by the larvacean Oikopleura dioica in tropical waters. J Plankton Res 17:205-220

Hopcroft RR, Roff JC (1998a) Production of tropical larvaceans in Kingston Harbour, Jamaica: are we ignoring an important secondary producer? J Plankton Res 20: 557-569

Hopcroft RR, Roff JC (1998b) Zooplankton growth rates: the influence of female size and resources on egg production of tropical marine copepods. Mar Biol 132:79-86

Hopcroft RR, Roff JC (1998c) Zooplankton growth rates: the influence of size in nauplii of tropical marine copepods. Mar Biol 132:87-96

Hopcroft RR, Roff JC, Bouman HA (1998a) Zooplankton growth rates: the larvaceans Appendicularia, Fritillaria and Oikopleura in tropical waters. J Plankton Res 20: 539-555

Hopcroft RR, Roff JC, Webber MK, Witt JDS (1998b) Zooplankton growth rates: the influence of size and resources of tropical marine copepodites. Mar Biol 132:67-77

Ikeda T, Hirakawa K (1996) Early development and estimated life cycle of the mesopelagic copepod Paraeuchaeta elongata in the southern Japan Sea. Mar Biol 126:261-270

Irigoien X, Castel J (1995) Feeding rates and productivity of the copepod Acartia bifilosa in a highly turbid estuary- the Gironde (SW France). Hydrobiologia 311:115-125

Kimmerer WJ, McKinnon AD (1986) Glutaraldehyde fixation to maintain biomass of preserved plankton. J Plankton Res 5:1003-1008

Kimmerer WJ, McKinnon AD (1987) Growth, mortality, and secondary production of the copepod Acartia tranteri in Westernport Bay, Australia. Limnol Oceanogr 32:14-28

Kimoto K, Uye SI, Onbé T (1986) Growth characteristics of a brackish-water calanoid copepod Sinocalanus tenellus in relation to temperature and salinity. Bull Plankton Soc Jpn 33:43-57

Klein Breteler WCM, Gonzalez SR, Schogt N, Fransz HG (1998) Feasibility of incubation experiments to estimate moulting rates in marine copepods. J Plankton Res 20: $257-269$

Liu H, Hopcroft RR (2006a) Growth and development of Neocalanus flemingeri/plumchrus in the northern Gulf of Alaska: validation of the artificial cohort method in cold waters. J Plankton Res 28:87-101

Liu H, Hopcroft RR (2006b) Growth and development of Metridia pacifica (Copepoda: Calanoida) in the northern Gulf of Alaska. J Plankton Res 28:769-781

McKinnon AD (1996) Growth and development in the subtropical copepod Acrocalanus gibber. Limnol Oceanogr 41:1438-1447

McKinnon AD, Duggan S (2003) Summer copepod growth and secondary production in subtropical waters adjacent to Australia's North West Cape. Mar Biol 143:897-907

McKinnon AD, Duggan S, Nichols PD, Rimmer MA, Semmens G, Robino B (2003) The potential of tropical paracalanid copepods as live feeds in aquaculture. Aquaculture 223: 89-106

McKinnon AD, Duggan S, De'ath G (2005) Mesozooplankton dynamics in inshore waters of the Great Barrier Reef. Estuar Coast Shelf Sci 63:497-511

McLaren IA (1978) Generation lengths of some temperate marine copepods: estimation, prediction, and implications. J Fish Res Board Can 35:1330-1342

Miller CB, Tande KS (1993) Stage duration estimation for Calanus populations, a modelling study. Mar Ecol Prog Ser 102:15-34

Miller CB, Johnson JK, Heinle DR (1977) Growth rules in the marine copepod genus Acartia. Limnol Oceanogr 22: 326-335

Miller CB, Huntley ME, Brooks ER (1984) Post-collection molting rates of planktonic, marine copepods. Limnol Oceanogr 29:1274-1289

Pearre S (1980) The copepod width-weight relation and its utility in food chain research. Can J Zool 58:1884-1891

Peterson WT, Hutchings L (1995) Distribution, abundance and production of the copepod Calanus agulhensis on the Agulhas Bank in relation to spatial variations in hydrography and chlorophyll concentration. J Plankton Res 17: 2275-2294

Peterson WT, Tiselius P, Kiørboe T (1991) Copepod egg production, moulting and growth rates, and secondary production, in the Skagerrak in August 1988. J Plankton Res 13:131-154

Richardson AJ, Verheye HM (1999) Growth rates of copepods in the southern Benguela upwelling system: the interplay between body size and food. Limnol Oceanogr 44: 382-392

Runge JA, McLaren IA, Corkett CJ, Bohrer RN, Koslow JA (1985) Molting rates and cohort development of Calanus finmarchicus and C. glacialis in the sea off southwest Nova Scotia. Mar Biol 86:241-246

Shreeve RS, Ward P, Murray AWA (1998) Moulting rates 
of Calanus helgolandicus: an intercomparison of experimental methods. J Exp Mar Biol Ecol 224:145-154

Tarling GA, Shreeve RS, Hirst AG, Atkinson A, Murphy EJ, Watkins JL (2006) Natural growth rates of Antarctic krill, Euphausia superba. I. Factors affecting inter-moult period and refinements to methods. Limnol Oceanogr 51: 959-972

Verity PG, Smetacek V (1996) Organism life cycles, predation, and the structure of marine pelagic ecosystems. Mar Ecol Prog Ser 130:277-293
Vidal J (1980a) Physioecology of zooplankton. I. Effects of phytoplankton concentration, temperature, and body size on the growth rates of Calanus pacificus and Pseudocalanus sp. Mar Biol 56:111-134

Vidal J (1980b) Physioecology of zooplankton. II. Effects of phytoplankton concentration, temperature, and body size on the development and molting rates of Calanus pacificus and Pseudocalanus sp. Mar Biol 56:135-146

Winberg GG (1971) Methods for the estimation of production in aquatic animals. Academic Press, London

Appendix 1. Details of model

\section{OVERALL PROCESS}

In general, the model works by first setting up a population from which samples are taken at random without replacement to make growth estimates. The population has characteristics such as stage duration, mean weight of a stage, and a distribution of age within stage. The age distribution can be either constant abundance with age, or linearly decreasing or increasing abundance with age. The first case represents a population with zero mortality; the second a population with either some mortality or a predominance of young copepods due to a recent reproductive burst; and the third a population with a reproductive burst in the past. These distributions are set up using a daily mortality value that can be negative; this selection, although artificial, makes it easy to set up the selected age distribution.

Each individual copepod therefore has an initial stage and age which are determined by sampling from the selected age distribution. In addition, each copepod has a randomly-selected deviation from the nominal development time, and a randomly-selected variation in log of initial weight. Random components are normally distributed with selected standard deviation.

Time in the model is represented non-dimensionally as a ratio to the duration of Stage 1, to reduce the number of parameters to be varied. This does not reduce the generality of the results. The population has no spatial structure.

We did not attempt to represent variability in growth rate in the environment, which can only be done experimentally. However, we did explore the influence of isochronal vs. non-isochronal life-stage distributions, with constant and declining growth with age, respectively, on estimates of growth. The first case had a mean stage duration of $1 \mathrm{~d}$ for all stages, and an equal rate of growth across all stages, based roughly on Acartia species (Miller et al. 1977). The second, non-isochronal case was based on Calanus pacificus (Vidal 1980a,b). The duration of stages and weight increments for these cases are given in Table 3.

The steps in model calculations are described below and summarized in Fig. 1, with reference to parameter names in Table 2.

\section{MODEL CALCULATIONS}

\section{Initializing population to be sampled}

The population age structure is sampled randomly from a continuous distribution of age from 0 (entry to the first stage) to the sum of the stage development times. A mortality value (which may be negative) is used to produce a uniform slope in log abundance with age, which is the probability density for sampling. Thus the probability density function is:

$$
P_{a}=\frac{\mathrm{e}^{-m a}}{\int_{0}^{D_{\mathrm{T}}} \mathrm{e}^{-m a} d a}
$$

where $m$ is daily mortality, $a$ is age, and $D_{\mathrm{T}}$ is development time through all stages

- Take $N$ random samples from the selected age distribution

- Calculate the nominal initial weight of each stage from w.init, the initial weight of Stage 1 and $G_{i}$ the specified weight gain per stage

- Calculate nominal specific growth rate by stage from growth and stage durations

- Calculate initial length at each stage from the lengthweight relationship using parameters $1 w$.params.

\section{Initializing each copepod}

Each copepod has a weight based on the initial weight in the stage, the increment due to its age within the stage, and a random component. Its length is determined through the nominal length-weight regression from weight without the age increment (Fig. 4).

$$
W_{i j}=W_{i} \cdot G_{i}^{a} \mathrm{e}^{N(0, c v \cdot L w)}
$$

where $W_{i j}$ is the weight of Copepod $j$ in Stage $i, W_{i}$ is the nominal weight on entry to Stage $i_{i} G_{i}$ is the ratio of weight on exit to weight on entry to Stage $i$, $a$ is relative age within stage (from 0 on entry to 1 on exit), and $N(0, C V . L w)$ is a normally distributed random variable with mean 0 and standard deviation of $\mathrm{CV} . \mathrm{LW}$. 
Appendix 1 (continued)

- Determine stage from age of each copepod and stage durations $D_{i}$

- Calculate initial weight from Eq. (A2)

- Calculate an initial length from individual weight not including the weight increment within the stage, using the nominal length-weight relationship

- Calculate relative development time as $D_{i} N(1$, cv.dtime $)$.

\section{Protocol for each simulated AC experiment}

- Draw samples of size $N_{\mathrm{f}}$ for each life stage from the population to determine weights by stage and the sample length-weight relationship by linear regression on logtransformed lengths and log-transformed weights

- For each of the $N_{\text {rep }}$ replicates, draw a sample of size $N_{t}$ from the population

o For an artificial cohort, the random sample is drawn from a Poisson distribution using a trapezoidal sampling window $L_{\mathrm{ac}}$ defining the lengths of copepods to be sampled o For a stage-based sample, the selected number of copepods is drawn from the stage(s) specified

- For artificial cohorts, if $P_{\min }>0$, additional copepods may be sampled from the initial population to represent inefficient size fractionation or 'leakage'

- For each final sample, determine stage, length, and weight (below)

- Calculate representative weights of the copepods in the samples by several alternative methods:

- Arithmetic mean of weights (assuming copepods are counted and bulk weighed)

- Weight based on life stages and weight by life stage determined above

- Mean weights determined from individual lengths using length-weight relationship o Mean weights determined from individual lengths using length-weight relationship, but trimmed to exclude extremes

- For each method of calculating weight, determine growth rate as the slope of log weight over the duration of the experiment.

\section{Protocol for each final sample in experiment}

- Use the copepod's relative development time, age within stage, and nominal development times for each stage to calculate final stage and age within stage

- For each stage or part of a life stage, determine growth rate and weight increment

- If $G_{\text {pen }}>0$, reduce growth rate of each individual by that fraction

- If the copepod grew past the last stage in the simulation, assign the final weight of the last stage plus the copepod's individual deviation from mean weight

- Determine length as the initial length of the new stage plus the copepod's individual deviation.

\section{Protocol for modified molt rate method}

This approach is based on Eqs. (1) \& (2)

- Draw a random sample of size $N_{t}$ from each life stage in the population

- Estimate the duration of each life stage as the relative incubation period $T$ divided by the fraction that molted to the next stage

- Determine mean weights of stages from the field population as above

- Determine the root of Eq. (2) with an optimizer to get $g_{\mathrm{i} 1}$. 